\title{
A rapid screening method to determine the susceptibility of bio-based construction and insulation products to mould growth
}

Stefanowski, Bronia; Curling, Simon; Ormondroyd, Graham

\section{International Biodeterioration and Biodegradation}

DOI:

10.1016/j.ibiod.2016.10.025

Published: 01/01/2017

Peer reviewed version

Cyswllt i'r cyhoeddiad / Link to publication

Dyfyniad o'r fersiwn a gyhoeddwyd / Citation for published version (APA):

Stefanowski, B., Curling, S., \& Ormondroyd, G. (2017). A rapid screening method to determine the susceptibility of bio-based construction and insulation products to mould growth. International Biodeterioration and Biodegradation, 124-132. [116]. https://doi.org/10.1016/j.ibiod.2016.10.025

\footnotetext{
Hawliau Cyffredinol / General rights

Copyright and moral rights for the publications made accessible in the public portal are retained by the authors and/or other copyright owners and it is a condition of accessing publications that users recognise and abide by the legal requirements associated with these rights.

- Users may download and print one copy of any publication from the public portal for the purpose of private study or research.

- You may not further distribute the material or use it for any profit-making activity or commercial gain

- You may freely distribute the URL identifying the publication in the public portal ?
}

Take down policy

If you believe that this document breaches copyright please contact us providing details, and we will remove access to the work immediately and investigate your claim. 


\title{
A RAPID SCREENING METHOD TO DETERMINE THE SUSCEPTIBILITY OF BIO-BASED CONSTRUCTION AND INSULATION PRODUCTS TO MOULD GROWTH
}

\author{
B.K Stefanowski ${ }^{\mathrm{a}}$, S.F Curling ${ }^{\mathrm{b}}$, G.A. Ormondroyd ${ }^{\mathrm{c}, \mathrm{d}}$ \\ aBioComposites Centre, Bangor University, Bangor, Gwynedd, LL57 2UW, United \\ Kingdomb.stefanowski@bangor.ac.uk \\ ${ }^{\mathrm{b} B i o C o m p o s i t e s ~ C e n t r e, ~ B a n g o r ~ U n i v e r s i t y, ~ B a n g o r, ~ G w y n e d d, ~ L L 57 ~ 2 U W, ~ U n i t e d ~}$ \\ Kingdom s.curling@bangor.ac.uk \\ 'BioComposites Centre, Bangor University, Bangor, Gwynedd, LL57 2UW, United \\ Kingdom \\ ${ }^{d}$ Department of Architecture and Civil Engineering, University of Bath, Bath, UK \\ g.ormondroyd@bangor.ac.uk
}

Corresponding author email b.stefanowski@bangor.ac.uk

\begin{abstract}
Mathematical models have been developed to evaluate materials' durability and susceptibility to biodeterioration by moulds, however models are material and mould species specific. Ultimately the best way to determine a materials' susceptibility is to expose the material to microorganisms. This study attempted to develop a quick, reliable screening method to evaluate a number of different materials for their susceptibility to moulds at optimal and limiting conditions. This test method was based on modified versions of ASTM 4445-91 and BSEN 846. The water absorption coefficient and Dynamic Vapour Sorption tests were also conducted to determine any correlation between the materials hygric properties and mould growth. The materials used to validate the novel screening method were: MDF, laminated MDF, Chipboard, Laminated chipboard, Wool, Hemp, Wood fibre insulation and pine. It was found chipboard was the most susceptible to mould growth and wool the least when in direct and indirect contact with agar. Primary colonisers ( $A$. niger) easily colonised the materials, regardless of the environmental conditions, whereas secondary $(A$. alternate) and tertiary ( $T$, virens) colonisers were absent on materials under limiting conditions.
\end{abstract}

Key Words: Mold, construction materials, insulation, susceptibility, moisture

\section{INTRODUCTION}

During the service life of buildings, bio based construction materials could be at risk of biodeterioration such as that caused as a result of the biotic processes of microorganisms. In the environment saprophytic organisms such as mould and decay fungi are the main agents responsible for the decomposition and recycling of organic matter. However, in the built environment they are associated with physical and aesthetic damage and human health problems such as allergic and toxic reactions (Airaksinen et al., 2004; Cooley et al., 1998; Jarvis and Miller, 2004; Mensah-Attipoe et al., 2015; Nielsen, 2003). Modern building practices have, in some cases, exaggerated this problem with increased insulation hindering ventilation, resulting in increased areas of condensation and subsequent mould growth (Schmidt, 2006). Moulds will readily colonise lignocellulosic materials but can also attack synthetic floor coverings, airplane fuels, oils, glues, paints and textiles (Pasanen et al., 1992; Schmidt, 2006). This ability to attack a wide variety of 
materials is enabled by the variety of physiological responses demonstrated by mould fungi in regards to temperature, water activity, relative humidity and $\mathrm{pH}$ (Schmidt, 2006).

Hygroscopic (water sorption) properties are an inherent characteristic of materials that influence both the application and microbiological resistance (Airaksinen et al., 2004; Xie et al., 2010). Natural fibres are hygroscopic because their cell walls contain high amounts of water sorption sites (hydroxyl groups) and can expand to accommodate the water (Xie et al., 2010). Moulds have been shown to appear in succession on a material as the moisture content of the material fluctuates, according to their minimum moisture demands of the mould, (Pasanen et al., 1992). Therefore, although the need for determining a materials' vulnerability to mould growth is obvious, it is clear that not all materials have equal susceptibility (Johansson et al., 2012; Mensah-Attipoe et al., 2015), which adds complexity when considering composite materials. Isopleths have been used to describe relationships between temperature, moisture and fungal growth on nutrient media and although isopleths can be very useful, they are, however, only suitable for predicting growth of known fungi on one material at a time and are time intensive (Johansson et al., 2013b). There have been a number of mathematical models developed and reported in recent years that can be used to evaluate durability and susceptibility of wood and wood-based materials to biological deterioration (Ojanen et al., 2007; Viitanen et al., 2010). Basic models are used to indicate mould germination conditions, such as the isopleth technique, but these do not account for fluctuations in environmental conditions. More advance models such as the VTT model and the bio-hygrothermal model (Sadovský et al., 2013) can be used but these have also shown significant variations in results due to simplifications and assumptions (Sadovský et al., 2013). There are, however, further disadvantages to using some models to predict microbiological growth, in that most are based on laboratory data, where optimum conditions are used, and are therefore often not comparable to construction materials, which are comprised of less nutrient rich materials (Clarke et al., 1999). Very rarely do they take into account species dominance (Gu and $\mathrm{Gu}, 2005)$. One key characteristic in predicting the susceptibility of materials requires a knowledge of the organisms' minimum water requirements, that are specific to the individual mould species (Nielsen et al., 2004). Models also do not consider the materials ability to absorb moisture, in contact or as vapour. It is possible that errors occur, due to a delay in a change in the surface conditions at different relative humidities, when compared to adjacent conditions.

These models may therefore not be the most applicable way of determining a materials' susceptibility to mould growth. As stated above, these models are often developed using the moulds optimal growing conditions and therefore, if materials are destined for use outside of these environmental ranges, such as furniture in a bathroom or kitchen, the level of biological attack may be based on false assumptions. Moulds can still colonise materials and grow in sub optimal conditions and it has been shown that even at low humidities, where substantive growth may be retarded or prevented, spores and mycotoxins can still be released (Abbott, 2002; Nielsen et al., 2004). This can be detrimental to both the material, as it may enable degradation by other fungal species and in the case of mycotoxins, to human health. It is highly important to understand how a mould responds to a different substrates and materials susceptibility to microbial attack. Any misunderstanding or poorly informed decisions can have damaging consequences to product industry, economy and human health (Gu, 2016; Gu and Gu, 2005; Mensah-Attipoe et al., 2015). 
Ultimately the best way to determine a materials' susceptibility to moulds is to physically test the subject material. The aim of this study was the development of a rapid screening method for evaluating the susceptibility of different materials to mould growth under varying conditions and methods of inoculation. The hygric properties of the materials tested were also determined in order to evaluate correlations between mould growth and the materials' hygric properties.

\section{MATERIALS AND METHODS}

The method described below, is a further development of the study conducted by Stefanowski et al (2015) which was derived from BS EN ISO 846: 1997 Plastics Evaluation of the action of microorganisms and ASTM D 4445-91 1991 Standard Method for Testing Fungicides for Controlling Sapstain and Mould on Unseasoned Lumber (Laboratory Method).

\subsection{Materials}

The materials tested include three commercial grade construction medium density fibre board (MDF), laminated MDF, chipboard and laminated chipboard and three commercial insulation materials sheep's wool, hemp and wood fibre insulation with solid pine wood (Pinus sylvestris) used as a control. The construction panel specimens were prepared to give an upper surface area of $30 \mathrm{~mm}^{2}$ with the thickness being that of the test material. As the insulation materials were 50 to $60 \mathrm{~mm}$ thick, a subsample of $5 \mathrm{~mm}$ thickness was removed from the top surface of the material for use as the test specimen.

\subsection{Preconditioning}

All specimens were conditioned in conditions of $23 \pm 1{ }^{\circ} \mathrm{C}$ and $60 \pm 3 \% \mathrm{RH}$ and once constant mass was reached the specimens were weighed. The specimens to be inoculated with moulds were sterilised with ethanol and water 70:30 (BSI 1997).

\subsection{Hygric}

The sorption dynamics of natural fibres are complex partly due to fibre internal structure and partly due to continuous nano-structural changes, associated with dynamic behaviour of cell walls (Xie et al., 2010). Two methods were used to determine the material's sorption properties; Dynamic Vapour Sorption (DVS) and water absorption coefficient (BSI 2002). Pine (Pinus sylvestris) was excluded from the hygric tests.

\subsubsection{Water absorption coefficient}

This was conducted following the standard BS EN ISO 15148 : 2002, Hygro-thermal Performance of Building Materials and Products - Determination of water absorption coefficient by partial immersion.

\subsubsection{Dynamic Vapour Sorption (DVS)}

DVS is designed to accurately measure weight changes of a sample (less than $10 \mathrm{mg}$ ), as it absorbs and desorbs moisture at differing relative humidities and temperatures. The sample was suspended in a microbalance within a sealed thermostatically controlled chamber, where a constant flow of dry nitrogen gas was passed over the sample at a flow rate of $200 \mathrm{~cm}^{3} \mathrm{~s}^{-1}$ and a temperature of $21 \pm 0.2{ }^{\circ} \mathrm{C}$ (Popescu et al., 2013). The inert gas carried a controlled quantity of water, maintaining a set $\mathrm{RH}$. The schedule for the DVS was set to start at $0 \% \mathrm{RH}$ and then 
increase in $5 \%$ steps up to $95 \%$ for the adsorption phase and the reverse for the desorption phase (Popescu et al., 2013). The DVS maintained a given $\mathrm{RH}$ until the weight change of the sample was less than $0.002 \% \mathrm{~min}^{-1}$. Mass change data were acquired every $20 \mathrm{~s}$. Sorption and desorption isotherms were produced for each material by plotting mass change against relative humidity $(\mathrm{RH})$.

\subsection{Mould tests}

\subsubsection{Moulds}

The mould species chosen for this experiment are based on standards used, however they are also consistently found in indoor environments (Cooley et al., 1998). The mould species were acquired from Fungal Biodiversity Centre, Institute of the Royal Netherlands Academy of Arts and Science (KNAW). The species selected were: Aspergillus versicolor (Vuill) CBS 117286, Cladosporium sphaerospermum (Penz) CBS 122.63, Chaetomium globosum (Kunze ex Fr.) CBS 107.14, Penicillium rubens (Biourge) CBS 401.92, Alternaria alternata ((Fr.) Keissl) CBS 120829, Paecilomyces variotti (Bainier) CBS 108945, Trichoderma virens (J.H. Mill, Giddens \& A.A. Foster) CBS 100946 and Aureobasidium pullulans (var.pullulans) CBS 101160.

On the basis of the minimal requirement of available water for fungal growth on material surfaces, indoor fungi and moulds can be divided into primary $\left(<0.80 \mathrm{a}_{\mathrm{w}}\right)$, secondary $\left(0.80-0.09 \mathrm{a}_{\mathrm{w}}\right)$ and tertiary colonisers $\left(>0.90 \mathrm{a}_{\mathrm{w}}\right)(\mathrm{WHO}, 2009)$. Using this definition the aforementioned moulds are divided into the appropriate colonisers. Primary colonisers; Aspergillus versicolor (Górny, 2004), Paecilomyces variotti (Górny, 2004) and Penicillium rubens (WHO, 2009). Secondary colonisers; Cladosporium sphaerospermum (Górny, 2004) and Alternaria alternata (Klarić et al., 2007). Tertiary colonisers; Chaetomium globosum (Klarić et al., 2007) and Trichoderma virens (Górny, 2004).

\subsubsection{Preparation of spores}

A mixed spore suspension, containing all of the selected mould species, was produced following the method described in BS EN 846 Plastics - Evaluation of the action of microorganisms 1997

\subsubsection{Inoculation and exposure}

The three mould tests were conducted using sterile $600 \mathrm{ml}$ vessels with aluminium lids.

For direct/indirect contact test, a mineral salt solution agar was used (BSI, 1997), which was autoclaved at $121^{\circ} \mathrm{C}$ for 15 minutes, cooled and $60 \mathrm{ml}$ was poured into each vessel.

To expose samples and moulds to a limited $\mathrm{RH}$, a saturated salt solution was used, mixed with sterilised deionised water, generating a $60 \% \mathrm{RH}$ within the vessels at 20 $\pm 2{ }^{\circ} \mathrm{C}$. Sterilised supports were added to each vessel to hold the sample in the centre of vessel. Figure 1 shows a diagram of how the samples were positioned in each of the tests. Two of the 6 replicate samples of each material were placed in one vessel.

Specimens were introduced to the vessel one at a time and placed according to test specifications. Samples for the relative humidity experiment were securely sealed to ensure no moisture loss or gain. Each sample for all three experiments was 
inoculated with $1 \mathrm{ml}$ of the mould spore solution. The vessels and sample were then stored in a dark chamber at $20 \pm 2{ }^{\circ} \mathrm{C}$ at $70 \pm 3 \% \mathrm{RH}$ for three weeks.

Each mould underwent a viability test on sterilised $4 \%$ malt agar plates $(40 \mathrm{~g}$ malt extract and agar $20 \mathrm{~g}$ in $1000 \mathrm{ml}$ ) apart from, for Chaetomium and Trichoderma moulds, where a $4 \%$ oatmeal agar culture was used. $1 \mathrm{ml}$ of the spore solution was pipetted onto the agar and spread using a sterile glass rod. The agar plates were then sealed with a wax film and incubated at $20 \pm 2{ }^{\circ} \mathrm{C}$ at $70 \pm 3 \% \mathrm{RH}$.

\subsubsection{Assessment}

After exposure to mould, the samples were removed from the vessel and visually evaluated for mould growth (Table 1). Where possible, primary, secondary and tertiary colonisers were identified and recorded. A rating of 1 (present) or 0 (absent) was given to the presence or absence of primary, secondary and tertiary colonisers. The occurrence of the colonisers was given as percentage across the replicates.

\section{RESULTS AND DISCUSSION}

\subsection{Wide Range of Moisture Properties}

The principle of the water sorption coefficient test was to measure the water absorption by partial immersion in water, by measuring the change in mass over time. Table 2 shows the results for water absorption coefficient. For this test, water absorption relies on capillary action (uptake) and in natural fibres this can cause the swelling of the material. As wood fibres can expand to accommodate additional water (Xie et al., 2010), for wood-based construction materials, the results should therefore be taken as indicative only.

Figure 2 shows the mass change over time. Chipboard had almost become saturated by the end of the 24 hour period, as the rate of water uptake decreased. In comparison, MDF and laminated MDF showed a slower, steady rate of water absorption. This could be due to a combination of variables between materials such as particle and resin distribution and the density difference between MDF and chipboard, $700 \mathrm{~kg} \mathrm{~m}^{-3}$ and $600 \mathrm{~kg} \mathrm{~m}^{-3}$ respectively. The laminated chipboard showed a slower rate of absorption due to its less permeable melamine coating. Wool and hemp materials became saturated within the first hour as these materials have a low density of $22.64 \mathrm{~kg} \mathrm{~m}^{-3}$ and $43.72 \mathrm{~kg} \mathrm{~m}^{-3}$ and therefore can hold less water proportionally within matrix before becoming saturated. Wood fibre insulation has a density of $205.03 \mathrm{~kg} \mathrm{~m}^{-3}$, therefore absorption was slower but the sample still became saturated within 5 hours. The test for all three insulation materials, ceased after four hours, as water was absorbed through to the top surface of the sample.

The data (figure 3) derived from the DVS shows that all the materials exhibited varying levels of hysteresis (the difference in EMC (equilibrium moisture content) dependent on sorption or desorption) with them all exhibiting IUPAC type 2 sorption and desorption isotherms (Hill et al., 2009). The construction materials all exhibited significant hysteresis effect, though in contrast hemp and wool showed only a small hysteresis effect. This could be related to the materials densities and higher lignin content of the wood-based materials (Hill et al., 2009).

Table 2 show the maximum moisture content (EMC) of the material when exposed to humidity of $95 \%$. Hemp absorbed the most moisture at $95 \% \mathrm{RH}$ with $20 \%$ of dry weight and laminated MDF the least at $14.18 \%$. Laminated materials have lower 
EMC values than un-laminated materials due to the presence of the less permeable melamine coating.

\subsection{Material Specific Mould Ecology}

Observations were made at the end of a three week period to evaluate the mould coverage over the sample (\%). Note was taken of the presence of primary, secondary and tertiary species, to give an indication of colonising mould succession and competition. The mineral salt agar was present to act as a moisture source and would not act as a carbon source for growth; therefore the mould fungi had to use carbon derived from the samples i.e. utilisation of the sample material $(\mathrm{Gu}, 2016)$. Although moulds had successfully grown in all vessels there were differences dependent on the material and exposure method.

For contact samples, the chipboard had the highest intensity of growth, (5 rating). Laminated chipboard, hemp and pine had the second highest, (4 rating). Figure 5 shows that in the vessels containing chipboard and dense wood fibre, all moulds were present, as primary, secondary and tertiary colonisers were observed. This corresponds to previous work where the greater availability of free water in the structure of the chipboard (Górny, 2004) enhanced its susceptibility to moulds. The data derived from the DVS studies also shows that the chipboard and dense wood fibre had higher moisture contents than the other materials at similar relative humidity levels. However, greater intensity of growth was observed on chipboard, showing a greater susceptibility to moulds than the other materials tested which may be due to availability of nutrients and a preference of the moulds.

In contrast the least intensity of growth was observed on MDF and wool - with MDF exhibiting lower nutrient availability than chipboard, because it is processed wood fibre (Johansson et al., 2013a). This shows that moulds attack materials suited to their chemical and physical capabilities and material composition (Gu, 2003).

For indirect contact, chipboard (both un-laminated and laminated) had the most intense growth, with a rating of 5 and 4 respectively. All materials showed a reduced intensity of growth when not in direct contact with the agar, expect wood fibre insulation and laminated chipboard (Table 3). This may be indicative that the sample's hygric properties enhance mould growth through the sorption of moisture from the agar. However, the presence of primary, secondary and tertiary colonising moulds are similar in both set of samples.

From figure 5 it can be observed that primary, secondary and tertiary colonisers were present in all vessels on all samples. It should be noted that where tertiary colonisers occurred $>80 \%$ of replicates, Trichoderma virens and Chaetomium globosum were the prevalent moulds. Trichoderma sp. where present, had excellent growth, which in other studies has been attributed to its production of antifungal products (Šegvić Klarić et al., 2007) that enable it to outcompete other fungal species (Ghisalberti and Sivasithamparam, 1991; Wiest et al., 2002).

Figure 4 graphically shows the difference in mould growth between contact and indirect contact samples. All growth on all materials in contact with agar had a higher intensity of mould growth compared to indirect contact samples, although not statistically different, except for chipboard. This shows the influence of the presence of the moisture in the agar on a sample's MC and subsequently, mould growth. However, materials with higher water absorption coefficient and MC values, did not necessarily have the highest intensity of growth.

There were no clear correlations between water absorption and mould growth as those materials with high levels of water sorption did not always show the highest 
levels of colonisation. Hemp had the highest water absorption coefficient but showed lower growth intensity than laminated chipboard. This reduced intensity of growth hemp than chipboard and thus prevented other mould growth. Also, wool samples had high hygric values of sorption but the lowest levels of growth. This is due to the limits of the moulds themselves, as they are not capable of decaying such materials. Using hygric data, materials can be assigned a 'critical moisture level' where moulds can develop on the materials. These results show that moisture environment alone is not enough to model the likelihood of mould growth, as other factors such as material composition and mould species capabilities and preference, have a major influence on comparative growth between materials. The hygric data does illustrate an important point that although some materials may not sustain heavy mould growth, they can easily absorb water. This factor may influence fungal growth on other materials if they are used in conjunction (Curling et al., 2015).

When analysing these results, it was observed that there were differences in the presence of primary, secondary and tertiary colonisers (Figure 5). A value of 1 represents the presence of primary, secondary or tertiary colonisers across all replicates. All samples and replicates had primary species colonising the samples in contact, indirect contact and at $60 \% \mathrm{RH}$. No secondary or tertiary colonisers were observed on any material when cultivated at $60 \% \mathrm{RH}$. This shows that building materials can form small niches in indoor environments for different organisms (Mensah-Attipoe et al., 2015).

Figure $5 \mathrm{~A}$ and $5 \mathrm{~B}$ shows the succession of growth on MDF and laminated MDF respectively. The frequency of growth of secondary and tertiary colonisers was significantly reduced when samples were out of contact with agar and at $60 \% \mathrm{RH}$. However, on MDF, secondary colonisers were still present even when out of contact with the agar, whereas on Laminated MDF the frequency of growth of secondary colonisers was reduced. This shows that a change in the surface of a material can alter the susceptibility to different mould species. Laminated chipboard and chipboard revealed a similar pattern.

Figure 6 shows the combined data of intensity of growth and frequency of colonisers for materials in direct contact with agar. It illustrates that different materials, exposed to the same moulds under the same conditions, experience differing colonisation patterns. Chipboard showed that with a high intensity of growth, there is a full succession of colonisers, whereas laminated chipboard, while exhibiting a similar intensity of growth, had reduced incidence of tertiary colonisers. Wool samples, showed a high, almost full succession of growth but the intensity of growth was the lowest of all materials tested. This is important as it demonstrates the usefulness of the test method in identifying the differing response of the the organisms to the different materials. In the case of wool, moulds can colonise and survive on the wool, likely surviving off contaminents in the insulation (Górny, 2004; Johansson et al., 2013a) which, again is highly important when considering real life scenarios where different materials are used in conjunction.

Many mould growth models rely on known optimum conditions for specific moulds and assume uniform susceptibility of different species of mould spores (Viitanen et al., 2010). However, in real life, environmental conditions in buildings are rarely optimal and fluctuate (Johansson et al., 2013a; Pasanen et al., 2000) so it is crucial to know the extreme limits for mould growth, as different mould species may be either actively growing or just surviving on a material. 
From the DVS isotherms, it can be observed that different materials absorb vapour at different rates at different $\mathrm{RH}$. It is considered that the limit value of relative humidity is between $70-90 \%$ for fungal growth on building materials (Pasanen et al., 2000). However, as mould species have differing limiting conditions, a study was made to determine the effects on colonisation, growth and competition at a lower limit of $60 \% \mathrm{RH}$. This showed that only primary colonising moulds were observed growing on construction materials at $60 \% \mathrm{RH}$ (Figure 5).

Table 3 shows the differences in intensity of growth at $60 \%$ on different materials. The highest moisture content observed was that of chipboard, at just under $10 \% \mathrm{MC}$ and this is generally considered too low for mould growth, although in this study mould growth was obvious on all samples. This could be a result from the initial equilibration period, following inoculation, where water availability was slightly higher. After which time the mould growth rate reduced but primary colonisers were largely established. It was observed that the most intense growth was on the woodbased materials, with chipboard showing the greatest growth (2 rating). This is highly important as there is evidence that Penicillium species are strong indoor contaminants and contribute significantly to SBS (Abbott, 2002; Cooley et al., 1998). No secondary or tertiary growth was observed in any vessels. This is due to the MC requirements of the mould species, as only xerophyllic moulds (dry loving) such as Aspergillus and Penicillium species were observed, which require $<0.80 \mathrm{a}_{\mathrm{w}}$ (Pasanen et al., 2000a). The same was observed by Pasanen et al., 2000 were xerophyllic moulds have great prevalence at low water activity. Secondary and tertiary colonisers are more hydrophyllic moulds and require higher levels of moisture to successfully grow and colonise a material.

Figure 6 graphically depicts the differences between intensity of growth of mould on sample materials in contact and indirect contact, at optimal conditions and at $60 \%$ $\mathrm{RH}$. It highlights the differences between growth at optimal and less than optimal conditions, which is important to understand these relationships as moulds can still produce metabolites and mycotoxins at low $\mathrm{RH}$ and temperatures (Nielsen et al., 2004). Statistically there is a difference between intensity of growth between test conditions on materials tested, except for MDF and laminated MDF. This indicates that MDF may have a lower MC requirement to support mould growth.

The results also show that moulds will grow on all materials even at limiting conditions, albeit with reduced growth. This suggests that testing specific material characteristics on a small scale may not be representative of the full product, due to bulk effects, especially when considering composite materials.

\subsection{Fast and Versatile Method}

This rapid screening method took only 3 weeks to obtain data on a materials' susceptibility to mould growth. However, consideration must be given to time as an influencing factor for mould growth (Vereecken and Roels, 2012). If a mould species is known to have a slow growth rate, extra time should be provided. It has an advantage over BS EN 846 in that it can be used for a range of materials and not just plastics. The method uses the principle from ASTM D 4445 to use a support, which can be used to evaluate the vulnerability of the material as a "carrier" of moulds. This may be important when considering wall constructs. As with wool for example, although all moulds were present, the intensity of growth on the wool itself was minimal in both situations but the mould growth on wool implies it will not act as barrier for more vulnerable materials such as MDF. This can result in the spread of moulds and may increase the materials and adjacent materials vulnerability to 
degradation fungi. Testing materials at lower $\mathrm{RH}$ can show which, if any species can survive and continue to utilise the material. This is especially important when considering drying materials, particularly after water damage (A.-L. Pasanen et al., 2000).

Although in this study a mixed spore suspension of commonly used test strains was used, the method is equally adaptable for use with specific single mould types or a mix of test or naturally isolated fungal strains. The method is also adaptable for study of any construction or insulation material and the test environmental conditions can be altered to simulate particular environmental conditions a material is intended for. Using the $600 \mathrm{ml}$ vessel over thinner agar plates, enables the testing of whole thickness samples rather than thinner sample. This is highly beneficial especially when testing composite materials. At full thickness, the sample is more representative of the product and the interactions with moisture and subsequent mould growth are more comparable with the product in service. It is also beneficial as it tests any bulk effects of the product.

\section{Conclusion}

Identification of susceptible materials and mould growth patterns is highly important, especially when considering toxic moulds. This study developed a rapid screening method to enable the determination of the susceptibility of different materials to different mould species. The method provides data enabling identification of more vulnerable materials, materials that may have synergistic with other materials, material responses to varying moisture environments and consequential mould growth dynamics under varying environmental conditions: data which is unlikely to be obtained by modelling alone.

\section{ACKNOWLEDGEMENTS}

This project has received funding from the European Union's Seventh Framework Programme for research technological development and demonstration under grant agreement no 609234.

\section{REFERENCES}

ASTM D 4445-91 : 1991, Standard Method for Testing Fungicides for Controlling Sapstain and Mould on Unseasoned Lumber (Laboratory Method) ASTM International, West Conshohocken, PA, 1991

BSI (1997) EN ISO 846 : 1997, Plastics - Evaluation of the action of microorganisms, Second edition 1997. British Standards Institute

BSI (2002) BS EN ISO 15148 : 2002, Hygro-thermal Performance of Building Materials and Products - Determination of water absorption coefficient by partial immersion. British Standards Institute

Abbott, S.P., 2002. Mycotoxins and Indoor Molds. Indoor Environ. Connect. 3.

Airaksinen, M., Kurnitski, J., Pasanen, P., Seppänen, O., 2004. Fungal spore transport through a building structure. Indoor Air 14, 92-104. doi:10.1046/j.1600-0668.2003.00215.x

Clarke, J.A., Johnstone, C.M., Kelly, N.J., McLean, R.C., anderson, J.A., Rowan, N.J., Smith, J.E., 1999. A technique for the prediction of the conditions leading to mould growth in buildings. Build. Environ. 34, 515-521. doi:10.1016/S03601323(98)00023-7 
Cooley, J.D., Wong, W.C., Jumper, C.A., Straus, D.C., 1998. Correlation between the prevalence of certain fungi and sick building syndrome. Occup. Environ. Med. 55, 579-584. doi:10.1136/oem.55.9.579

Curling, S., F., Stefanowski, B.K., Mansour, E., Ormondroyd, G.A., 2015. Applicability of wood durability testing methods to bio-based building materials, in: IRG Annual Meeting (ISSN 2000-8953). International Research Groupd on Wood Protection (IRG 46), Vina del Mar, Chile.

Ghisalberti, E.L., Sivasithamparam, K., 1991. Antifungal antibiotics produced by Trichoderma spp. Soil Biol. Biochem. 23, 1011-1020. doi:10.1016/00380717(91)90036-J

Górny, R.L., 2004. Filamentous Microorganisms and Their Fragments in Indoor Are A Review. Ann. Agric. Environ. Med. 11, 185-197.

Gu, J.-D., 2016. Biodegradation Testing: So Many Tests, but Very Little New Innovation. Appl. Environ. Biotechnol. 1. doi:10.18063/AEB.2016.01.007

Gu, J.-D., 2003. Microbiological deterioration and degradation of synthetic polymeric materials: recent research advances. Int. Biodeterior. Biodegrad. 52, 69-91. doi:10.1016/S0964-8305(02)00177-4

Gu, J.-G., Gu, J.-D., 2005. Methods Currently Used in Testing Microbiological Degradation and Deterioration of a Wide Range of Polymeric Materials with Various Degree of Degradability: A Review. J. Polym. Environ. 13, 65-74. doi:10.1007/s10924-004-1230-7

Hill, C.A.S., Norton, A., Newman, G., 2009. The water vapor sorption behavior of natural fibers. J. Appl. Polym. Sci. 112, 1524-1537. doi:10.1002/app.29725

Jarvis, B.B., Miller, J.D., 2004. Mycotoxins as harmful indoor air contaminants. Appl. Microbiol. Biotechnol. 66, 367-372. doi:10.1007/s00253-004-1753-9

Johansson, P., Bok, G., Ekstrand-Tobin, A., 2013a. The effect of cyclic moisture and temperature on mould growth on wood compared to steady state conditions. Build. Environ. 65, 178-184. doi:10.1016/j.buildenv.2013.04.004

Johansson, P., Ekstrand-Tobin, A., Svensson, T., Bok, G., 2012. Laboratory study to determine the critical moisture level for mould growth on building materials. Int. Biodeterior. Biodegrad. 73, 23-32. doi:10.1016/j.ibiod.2012.05.014

Johansson, P., Svensson, T., Ekstrand-Tobin, A., 2013b. Validation of critical moisture conditions for mould growth on building materials. Build. Environ. 62, 201-209. doi:10.1016/j.buildenv.2013.01.012

Mensah-Attipoe, J., Reponen, T., Salmela, A., Veijalainen, A.-M., Pasanen, P., 2015. Susceptibility of green and conventional building materials to microbial growth. Indoor Air 25, 273-284. doi:10.1111/ina.12140

Nielsen, K., Fog, 2003. Mycotoxin production by indoor molds. Fungal Genet. Biol. 39, 103-117. doi:10.1016/S1087-1845(03)00026-4

Nielsen, K.F., Holm, G., Uttrup, L.P., Nielsen, P.A., 2004. Mould growth on building materials under low water activities. Influence of humidity and temperature on fungal growth and secondary metabolism. Int. Biodeterior. Biodegrad. 54, 325-336. doi:10.1016/j.ibiod.2004.05.002

Ojanen, T., Viitanen, H., Peuhkuri, R., 2007. Modelling of Mould Growth in Building Envelopes - Existing models, discussion on improvement aspects, sensibility analysis. [WWW Document]. URL http://www.kuleuven.be/bwf/projects/annex41/protected/data/VTT\%20Oct\%20 2007\%20Paper\%20A41-T4-Fin-07-1.pdf (accessed 8.12.16). 
Pasanen, A.-L., Juutinen, T., Jantunen, M.J., Kalliokoski, P., 1992. Occurrence and moisture requirements of microbial growth in building materials. Int. Biodeterior. Biodegrad. 30, 273-283. doi:10.1016/0964-8305(92)90033-K

Pasanen, A.-L., Kasanen, J.-P., Rautiala, S., Ikäheimo, M., Rantamäki, J., Kääriäinen, H., Kalliokoski, P., 2000. Fungal growth and survival in building materials under fluctuating moisture and temperature conditions. Int. Biodeterior. Biodegrad. 46, 117-127. doi:10.1016/S0964-8305(00)00093-7

Pasanen, A.L., Rautiala, S., Kasanen, J.P., Raunio, P., Rantamäki, J., Kalliokoski, P., 2000. The Relationship between Measured Moisture Conditions and Fungal Concentrations in Water-Damaged Building Materials. Indoor Air 10, 111-120. doi:10.1034/j.1600-0668.2000.010002111.x

Popescu, C.-M., Hill, C.A.S., Curling, S., Ormondroyd, G., Xie, Y., 2013. The water vapour sorption behaviour of acetylated birch wood: how acetylation affects the sorption isotherm and accessible hydroxyl content. J. Mater. Sci. 49, 2362-2371. doi:10.1007/s10853-013-7937-x

Sadovský, Z., Koronthályová, O., Matiašovský, P., Mikulová, K., 2013. Probabilistic modelling of mould growth in buildings. J. Build. Phys. 1744259113496370. doi:10.1177/1744259113496370

Schmidt, O., 2006. Wood and Tree Fungi: Biology, Damage, Protection, and Use. Springer Science \& Business Media.

Šegvić Klarić, M., Kosalec, I., Mastelić, J., Piecková, E., Pepeljnak, S., 2007. Antifungal activity of thyme (Thymus vulgaris L.) essential oil and thymol against moulds from damp dwellings. Lett. Appl. Microbiol. 44, 36-42. doi:10.1111/j.1472-765X.2006.02032.x

Vereecken, E., Roels, S., 2012. Review of mould prediction models and their influence on mould risk evaluation. Build. Environ. 51, 296-310. doi:10.1016/j.buildenv.2011.11.003

Viitanen, H., Vinha, J., Salminen, K., Ojanen, T., Peuhkuri, R., Paajanen, L., Lähdesmäki, K., 2010. Moisture and Bio-deterioration Risk of Building Materials and Structures. J. Build. Phys. 33, 201-224. doi:10.1177/1744259109343511

Wiest, A., Grzegorski, D., Xu, B.-W., Goulard, C., Rebuffat, S., Ebbole, D.J., Bodo, B., Kenerley, C., 2002. Identification of Peptaibols from Trichoderma virens and Cloning of a Peptaibol Synthetase. J. Biol. Chem. 277, 20862-20868.

Xie, Y., Hill, C.A.S., Jalaludin, Z., Curling, S.F., Anandjiwala, R.D., Norton, A.J., Newman, G., 2010. The dynamic water vapour sorption behaviour of natural fibres and kinetic analysis using the parallel exponential kinetics model. J. Mater. Sci. 46, 479-489. doi:10.1007/s10853-010-4935-0 
Table 1: Visual assessment of mould growth (BSI, 1997)

\begin{tabular}{cc}
$\begin{array}{c}\text { Intensity of } \\
\text { growth }\end{array}$ & Evaluation \\
\hline 0 & No growth apparent under the microscope \\
1 & No visible growth to the naked eye but visible under a microscope \\
2 & Visible growth, up to $25 \%$ coverage \\
3 & Visible growth up to $50 \%$ coverage \\
4 & Visible growth up to $75 \%$ coverage \\
5 & Heavy growth, covering more than $75 \%$ of sample surface \\
\hline
\end{tabular}

546

547

Table 2: Water absorption coefficient and EMC of test materials at $95 \%$ and $60 \% \mathrm{RH}$

\begin{tabular}{|c|c|c|c|}
\hline Material & $\begin{array}{c}\text { Water absorption } \\
\text { coefficient }\left(\mathrm{Kg} /\left(\mathrm{m}^{2} \mathrm{hr}^{-1}\right)\right.\end{array}$ & $\begin{array}{c}\text { EMC at } 95 \% \\
\text { RH (\%) }\end{array}$ & $\begin{array}{c}\text { EMC at } 60 \% \\
\text { RH (\%) }\end{array}$ \\
\hline MDF & 3.25 & 17.46 & 7.92 \\
\hline Laminated MDF & 3.38 & 14.18 & 7.55 \\
\hline Chipboard & 4.65 & 18.01 & 9.39 \\
\hline Laminated chipboard & 4.25 & 16.58 & 9.28 \\
\hline Hemp & 5.28 & 20.92 & 4.02 \\
\hline Wood fibre insulation & 2.50 & 21.77 & 4.21 \\
\hline Wool & 4.50 & 19.17 & 11.78 \\
\hline
\end{tabular}

Table 3: Intensity of mould growth on sample in contact and indirect contact with agar and suboptimal conditions at $60 \% \mathrm{RH}$

\begin{tabular}{lccc}
\hline \multicolumn{3}{c}{ Material } & \multicolumn{3}{c}{ Intensity of growth } \\
\hline MDF & Contact & Indirect contact & $60 \% \mathrm{RH}$ \\
Laminated MDF & 3 & 2 & 1.8 \\
Chipboard & 3 & 2 & 1.6 \\
Laminated chipboard & 5 & 4 & 2 \\
Wool & 4 & 4 & 1.6 \\
Hemp & 2 & 1 & 0.4 \\
Wood fibre insulation & 4 & 3 & 1.6 \\
Pine & 3 & 3 & 1.2 \\
\hline
\end{tabular}


559
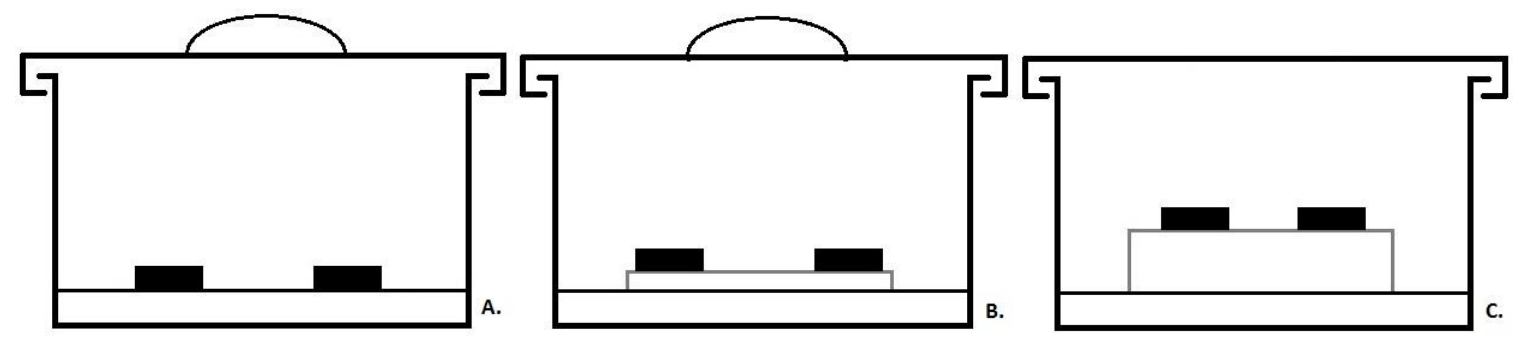

Fig 1: A; Sample in direct contact with agar, B; Sample indirect contact and C; Sample raised to the centre of the vessel $\mathrm{RH}$ test

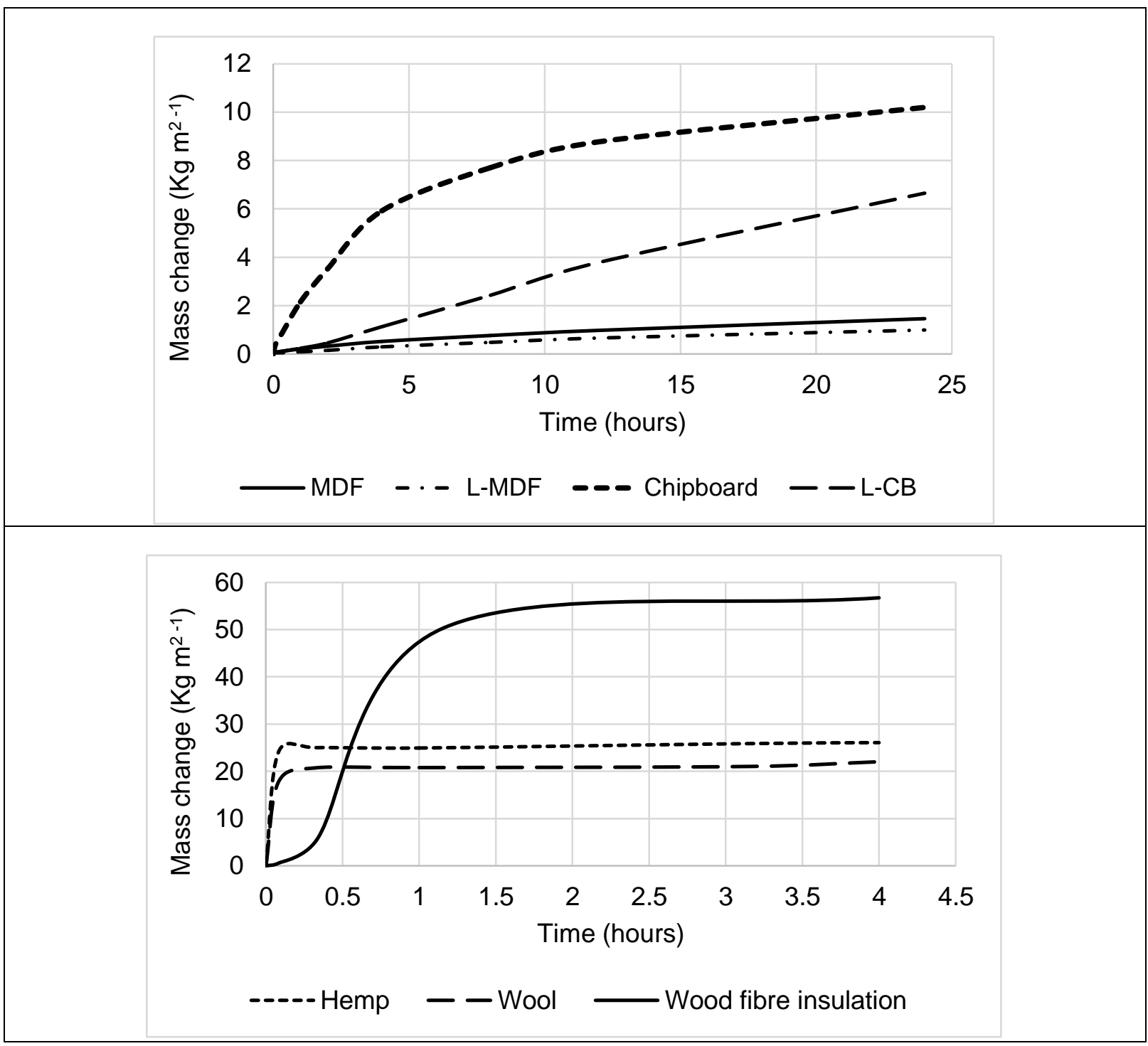

Fig 2: Water absorption of construction (a) and insulation (b) materials 


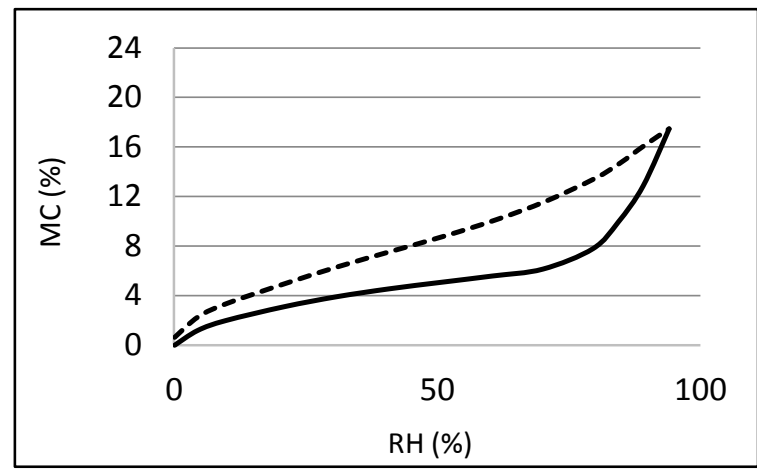

A: MDF

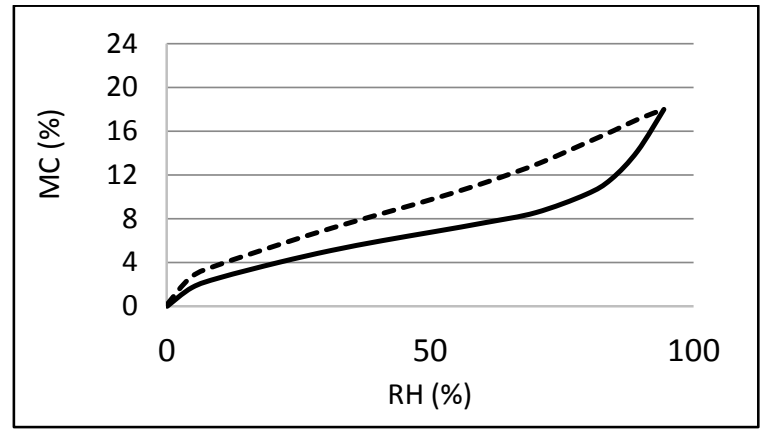

C. Chipboard

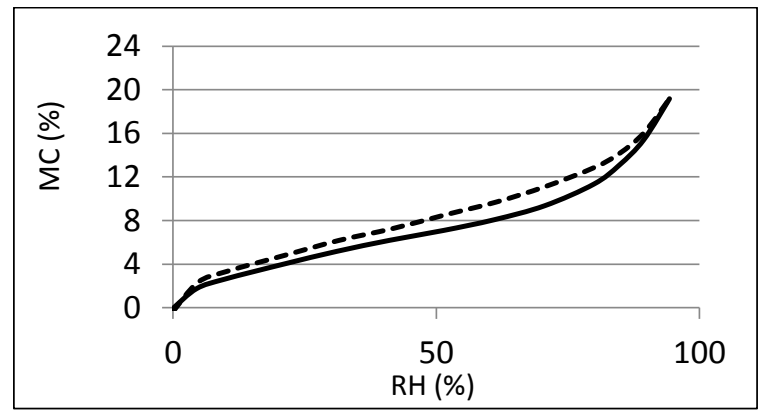

E. Wool

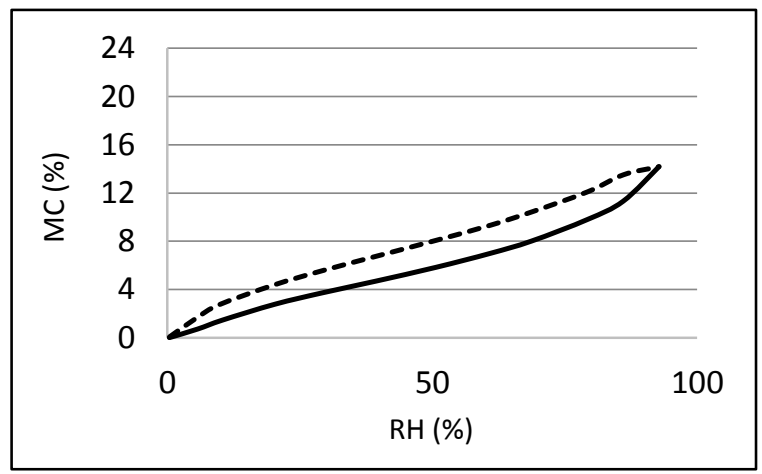

B. Laminated MDF

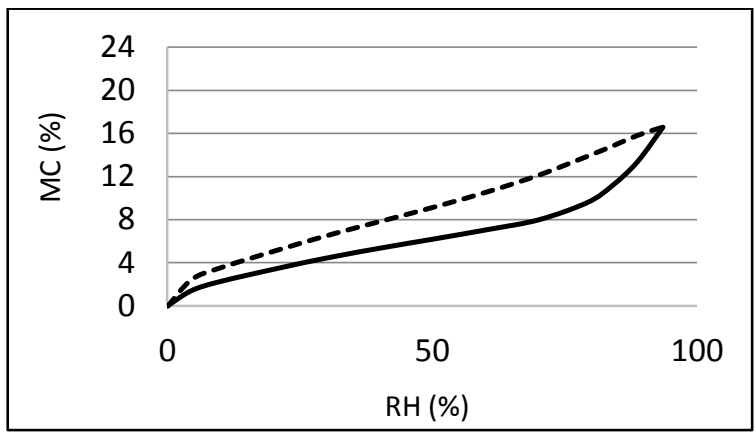

D. Laminated Chipboard

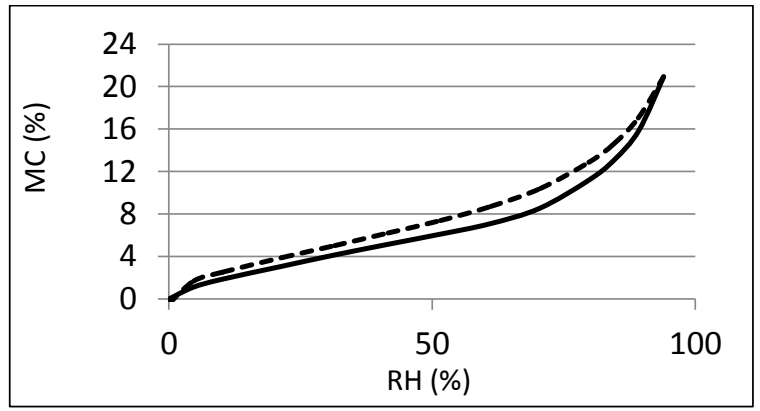

F. Hemp

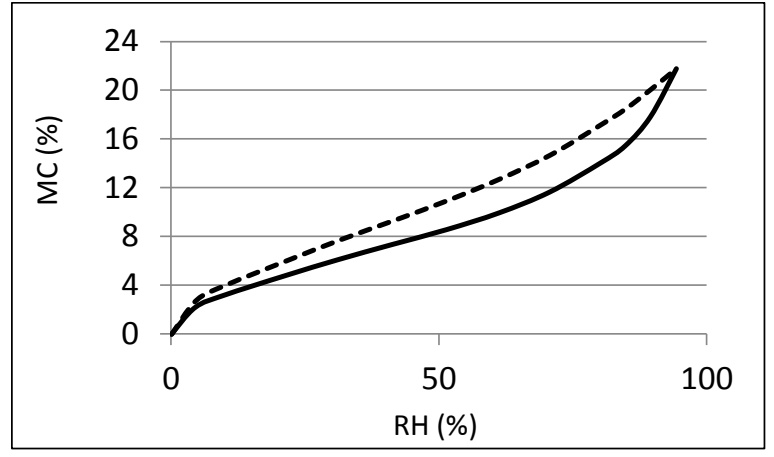

G. Wood Fibre insulation

Key

Fig 3: Mass change (MC) (\%) against $\mathrm{RH}(\%)$ isotherm curves 


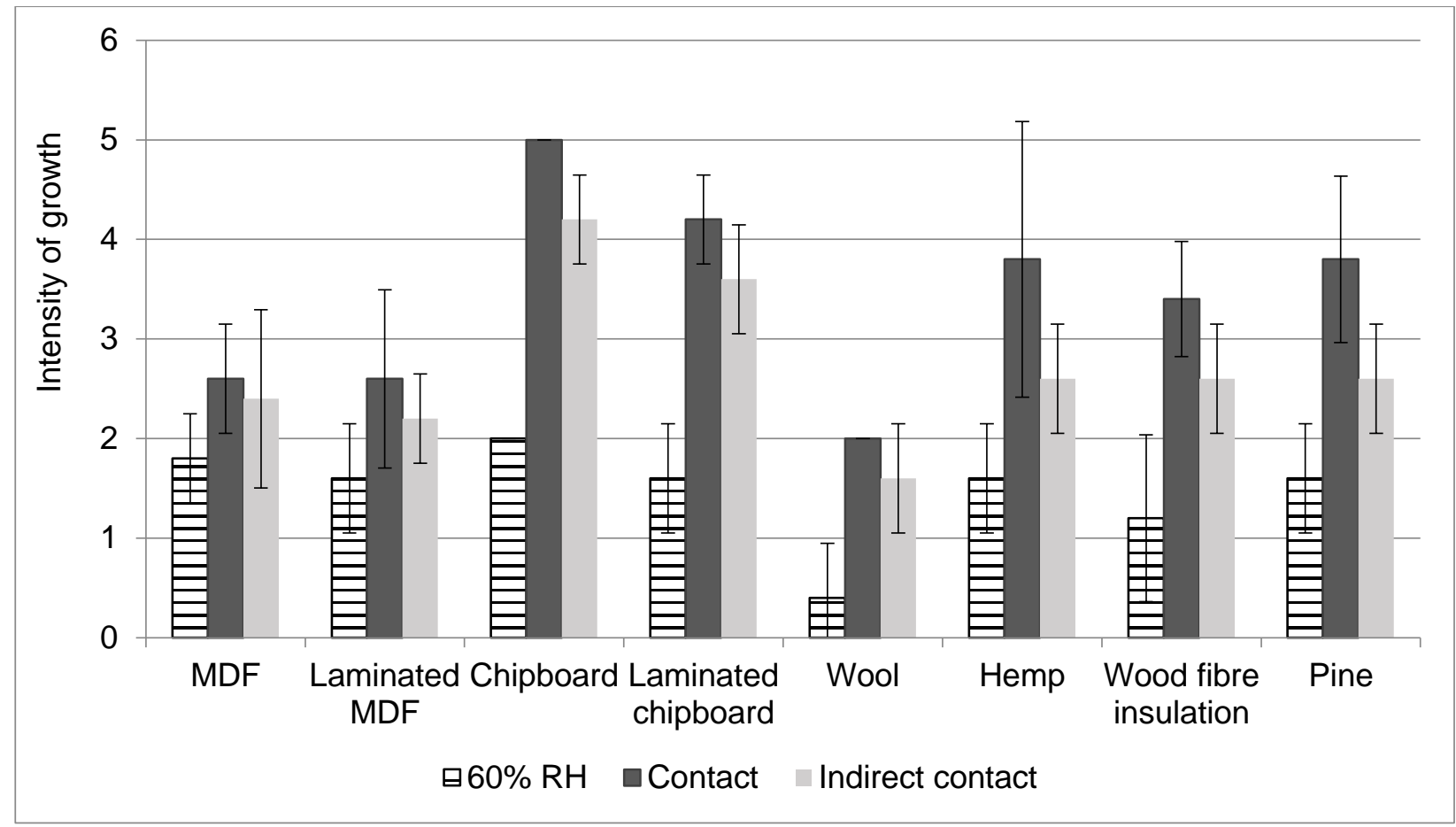

Fig 4: Intensity of growth, in contact, indirect contact and $60 \% \mathrm{RH}$ conditions 


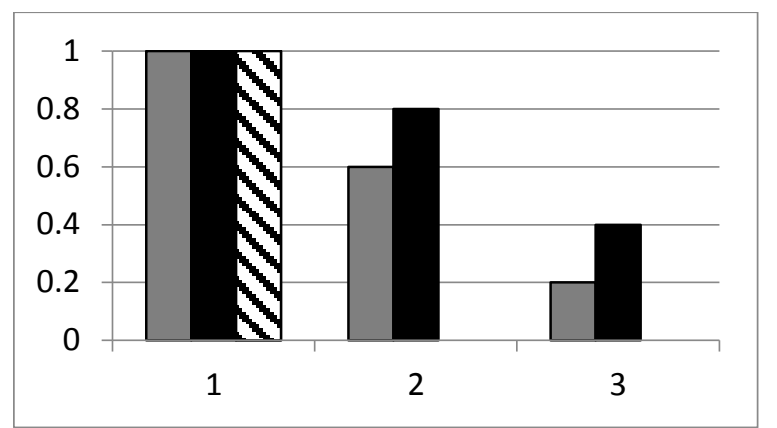

A: MDF

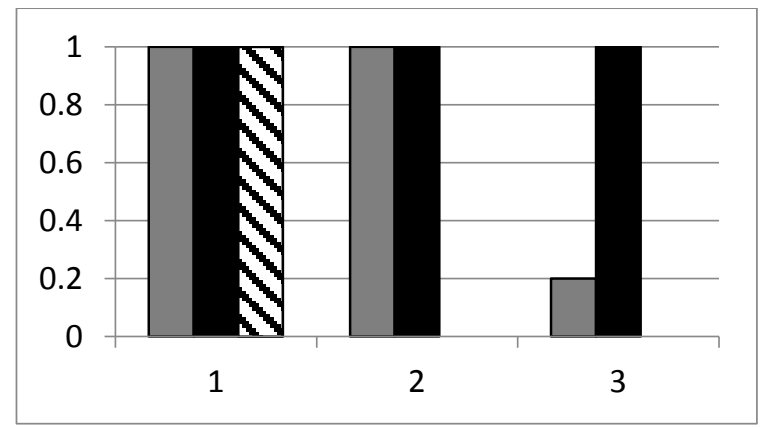

C. Chipboard

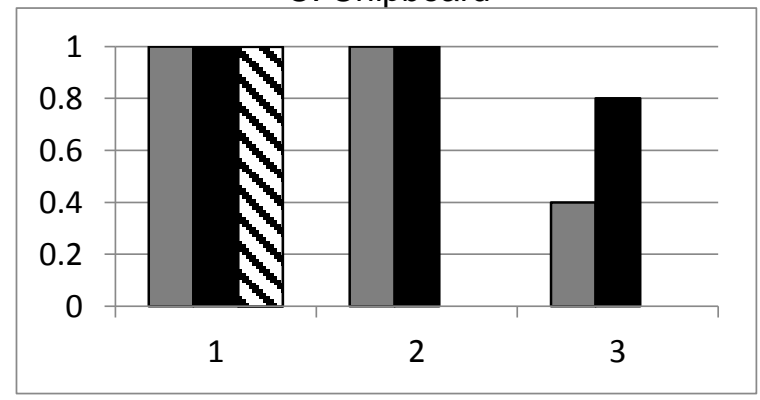

E. Wool

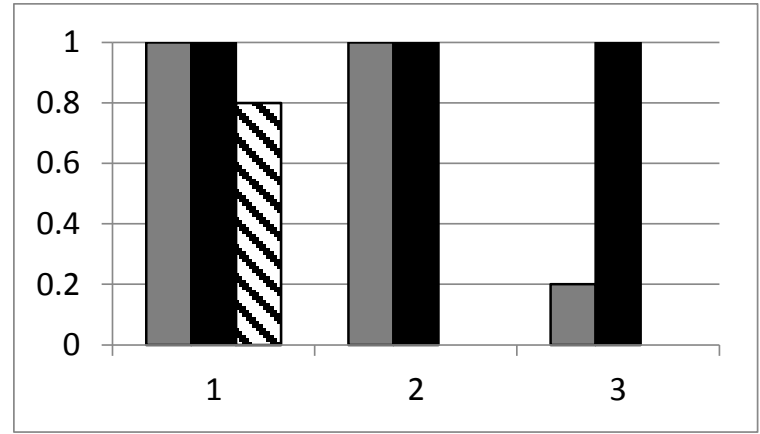

G. Wood Fibre insulation

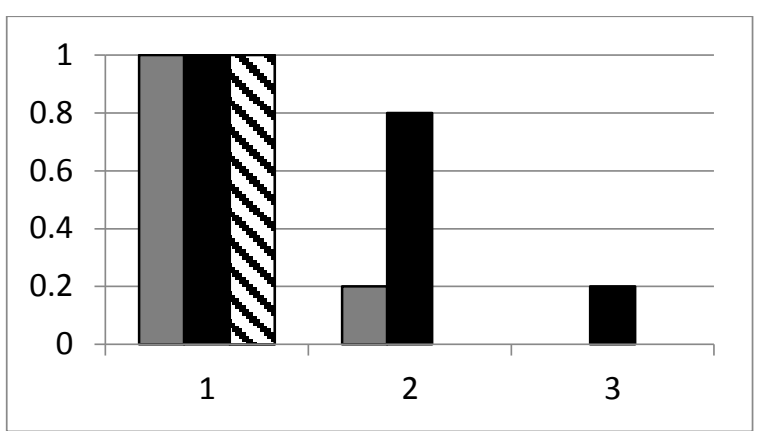

B. Laminated MDF

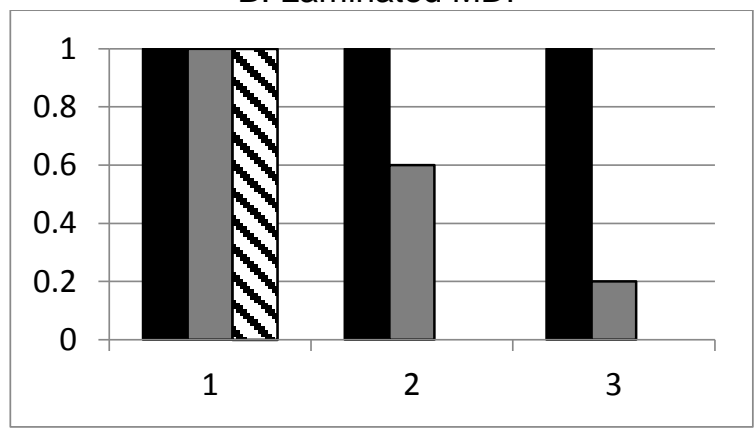

D. Laminated Chipboard

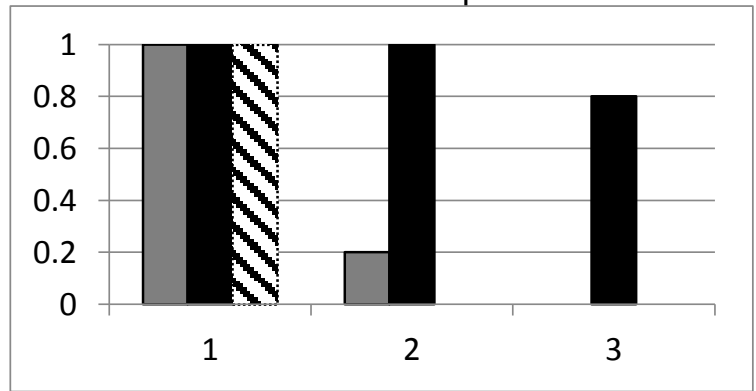

F. Hemp

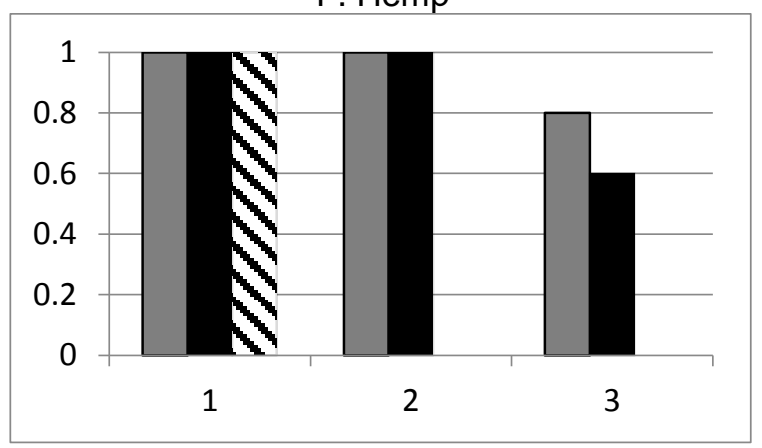

H. Pine
Fig 5: Frequency of growth by primary (1), secondary (2) and tertiary (3) colonisers on in contact (black), indirect contact (grey) and 60\% RH (stripe) 


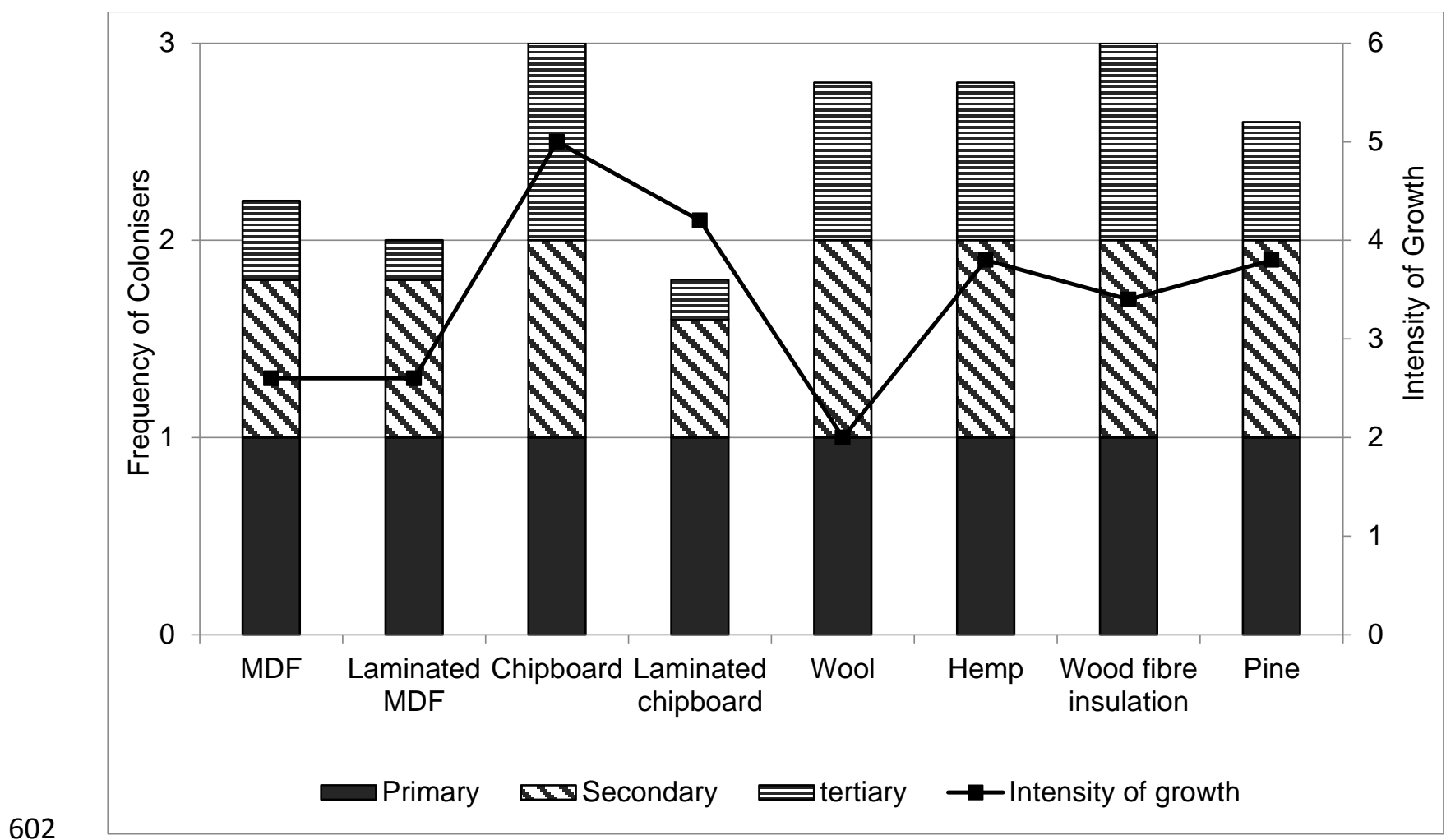

Fig 6: Intensity of growth and frequency of primary, secondary and tertiary colonisers on in contact samples 